IRA-International Journal of Education \& Multidisciplinary Studies

ISSN 2455-2526; Vol.13, Issue o3 (December, 2018)

Pg. no. 54-57.

Institute of Research Advances

Institute of

http://research-advances.org/index.php/IJEMS

\title{
Sustainable Sanitary Pad: A Case from Tamil Nadu
}

\section{Dr. Shankar Chatterjee}

Former Professor \& Head (CPME), NIRD \&PR, Hyderabad-500 030, Telangana, India.

Type of Work: Case Study (Editorial Contribution)

DOl: http://dx.doi.org/10.21013/jems.v13.n3.p4

\section{How to cite this paper:}

Chatterjee, S. (2018). Sustainable Sanitary Pad: A Case from Tamil Nadu. IRA International Journal of Education and Multidisciplinary Studies (ISSN 2455-2526), 13(3), 54-57.doi: http://dx.doi.org/10.21013/jems.v13.n3.p4

(C) Institute of Research Advances.

This work is licensed under a Creative Commons Attribution-Non Commercial 4.0 International License subject to a proper citation to the publication source of the work.

Disclaimer: The scholarly papers as reviewed and published by the Institute of Research Advances (IRA) are the views and opinions of their respective authors and are not the views or opinions of the IRA. The IRA disclaims of any harm or loss caused due to the published content to any party.

Institute of Research Advances is an institutional publisher member of Publishers Inter Linking Association Inc. (PILA-CrossRef), USA. The institute is an institutional signatory to the Budapest Open Access Initiative, Hungary advocating the open access of scientific and scholarly knowledge. The Institute is a registered content provider under Open Access Initiative Protocol for Metadata Harvesting (OAI-PMH).

The journal is indexed \& included in WorldCat Discovery Service (USA), CrossRef Metadata Search (USA), WorldCat (USA), OCLC (USA), Open J-Gate (India), EZB (Germany) Scilit (Switzerland), Airiti (China), Bielefeld Academic Search Engine (BASE) of Bielefeld University, Germany, PKP Index of Simon Fraser University, Canada. 


\begin{abstract}
According to the WHO survey conducted in October 2017 carried out across India including 35 cities viz., Bengaluru, Chennai, Cuttack, Delhi, Indore, Jaipur, Kanpur, Kolkata, Ludhiana, Mumbai, Ranchi, Srinagar, Surat and Thiruvananthapuramwomen respondents were contacted to get an idea about issues related to women. It has been revealed that about 43 percent of Indian women did not have access to sanitary essentials at the beginning of periods, while 36 percent felt uncomfortable in buying them with other customers around. Further, according to the survey report around 67 percent women have had to borrow a sanitary essential from a friend, colleague or family member. More than 45 percent women opined that menstruation was still considered a taboo in the society and 36 percent felt uncomfortable while buying sanitary essentials from a chemist shop in the presence of other customers. To address the situation at grassroots level many organizations have been working at different levels like awareness creation, producing of cheap sanitary pads etc. One such organization is Gramalayawhich has been operating in Thottiyam and Thathaiengarpet and Thuraiyur Block in the rural areas and in the slums of Tiruchirappalli City Corporation in Tiruchirappalli District. They are promoting sustainable sanitary pads by producing these through self-help Groups (SHGs). In this article based on a study carried on $1^{\text {st }}$ December 2018, a case is presented.
\end{abstract}

Key words: Health and Hygiene, Income Sanitary pads, Self-help Groups (SHGs) and Tamil Nadu

\title{
INTRODUCTION
}

According to the WHO survey conducted in October 2017 carried out across India including 35 cities viz., Bengaluru, Chennai, Cuttack, Delhi, Indore, Jaipur, Kanpur, Kolkata, Ludhiana, Mumbai, Ranchi, Srinagar, Surat and Thiruvananthapuram women respondents were contacted to get an idea about issues related to women. It has been revealed that about 43 percent of Indian women did not have access to sanitary essentials at the beginning of periods, while 36 percent felt uncomfortable in buying them with other customers around. Further, according to the survey report around 67 percent women have had to borrow a sanitary essential from a friend, colleague or family member. Another revealing point is that 45 percent informed that they had to borrow the sanitary napkins at least once or twice a year. More than 45 percent women opined that menstruation was still considered a taboo in the society and 36 percent felt uncomfortable while buying sanitary essentials from a chemist shop in the presence of other customers, (outlookindia.com/website).

To address the issue at grassroots level many organizations have been working at different levels in the country like awareness creation, producing of cheap sanitary pads etc. One such organization is Gramalaya which has been operational in Thottiyam and Thathaiengarpet and Thuraiyur Block and in the slums of Tiruchirappalli City Corporation in Tiruchirappalli District. They are promoting sustainable sanitary pads. These are produced by selfhelp Groups (SHGs). In this research paper, based on study carried on $1^{\text {st }}$ December 2018 a case is presented.

Gramalaya was established in 1987 with a group of committed youths in the field of rural development under the leadership of Sri S.Damodaran, Chief Executive Officer (CEO) and Founder. Gramalaya has got its legal entity by registering under the Indian Trust Act of 1882 in the year1987. The main objective of Gramalaya is to work for the amelioration of socially downtrodden people under the integrated rural development approach. Since 1987, Gramalaya has been operating in Thottiyam and Thathaiengarpet and Thuraiyur Blocks and in the slums of Tiruchirappalli city. Health and hygiene education, promotion of self-help groups among rural, urban and tribal women, construction of low-cost latrines and safe water supply through micro-credit are the major activities of the organization (gramalaya.in/about_gramalaya).

One of the important activities of Gramalaya for the welfare of the society is an innovation of cheapest reusable cloth pad for menstrual hygiene management which is called as FeelFree reusable cloth pads, under the banner of FeelFree title as a registered trade mark. Gramalaya felt the need to produce such clothes because it worked with adolescent girls in the Government schools of Tamil Nadu with the grant-support of Bank of America Merrill Lynch Capital under its corporate social responsibility (CSR) initiatives for menstrual hygiene and girls friendly toilets promotion in schools. During that time, it was observed that girls in schools were not aware of menstrual hygiene practices. One of the main reasons for school dropout or absence during school hours is the menstrual periods. In view of this, Gramalayadecided to promote sustainable pads at a cheap rate so that school girls even economically weak may use. These pads are cloth pads to absorb the menstrual flow during a woman's period, an alternative to disposable sanitary napkins or to reusable menstrual cups. Further, these are less expensive than disposable pads, reduce the amount of waste produced and also have health benefits, (feelfreeclothpads.com). 
Vision and Mission of the Organization: It can broadly be classified into two categories.

$>$ Creating awareness on Menstrual Hygiene Management and practices among women and adolescent girls in India.

$>$ Promoting reusable cloth pads to protect our environment and the health of women.

According to the officials of Gramalaya, the disposable pads are whitened with chlorine bleach, which produces a toxic byproduct called dioxin. Further, disposables pads also contain plastic chemicals and pesticide residue, but their pads are free from all these.

FeelFree Reusable Cloth Pads: For the benefit of readers steps for using the pads as mentioned by the organization are mentioned so that it can be promoted in other parts of the country among adolescent girls.

$\checkmark$ First Step: As a first step, used cloth pads have to be soaked in ordinary clean water for about 30 minutes

$\checkmark$ Second Step: Washing soap or washing powder should be used to wash the clothes.

$\checkmark \quad$ Third Step: Brush etc. should not be used during washing.

$\checkmark$ Fourth Step: It should be rinsed with normal water.

$\checkmark$ Fifth Step: The pads have to be dried in direct sunlight.

$\checkmark$ Sixth Step: Please see the washed cloth pads should be safe from pests and dusts while ii is in sunlight

$\checkmark$ Lastly: Pouch is available for keeping used cloth pad while in working place/school/colleges and after returning to home it can be washed for re-use.

\section{Field situation:}

To get an idea about the field situation of the production of sustainable sanitary pad, a study was carried out on $1^{\text {st }}$ December 2018 for which the functionaries of Gramalaya and group leaders of two SHGs were contacted. Based on the study, the research paper is written. It is pertinent to mention that two self - help groups (SHGs) viz. Poonthottam and Tamil Murasu were involved from 2016 in producing the sustainable sanitary cloth-pads at Poonthottam village, Thottiyam block in Tiruchirappalli district of Tamil Nadu. Each self-help group consisted of 20 women members and thus altogether 40 women were involved in this activity. The members belonged to backward caste (BC) and most backward caste (MBC) community and all members had school education. Prior to starting of producing sanitary pads, they were trained by Gramalaya in the year 2016. It is pertinent to mention that Poonthottam SHG was established in 2002 and Tamil Murasu's year of creation was 2001.Before producing of pads, the SHG members were involved in food-producing activities in a small way from the year of their establishments. The activities inter alia were making of banana flower pickle and banana fiber pickle (fiber comes out from the stem of banana); millet health drink, millet biscuit, etc. But keeping in need of the health and hygiene of adolescent girl during the menstrual period as mentioned already, the founder cum CEO of the NGO Sri S Damodaran motivated SHG members to start sanitary pad making unit, as the area had favourable backward and forward linkages. While interacting with the members, they informed that raw materials were collected from Thiruppur, 120 kilometers away from their village. Regarding marketing of the products, the members informed the same was done by an established agency known as GREAT (P) and also available on line. In addition, Amazon.com and Flipkart sell these. Further, in mela etc. the members visit for selling of the items. To a query about earning of each member, the group leaders informed that average earning per member per month hovered around Rs.9000.

They further informed that each member of the SHG used to save at the rate of Rs.100 per month as saving is mandatory for each member of the SHG. Both the SHGs were extended bank loan, three times each. For instance, Poonthottam SHG was an extended loan of Rs.40,000 in 2005, after repayment second dose was given in 2010 which was Rs.3 lakh. And in 2012, the third loan was given to the tune of Rs.5 lakh. On the other hand, loan amounts of Tamil Murasu were Rs.25,000 in 2001, Rs.1.50 lakh in 2005 and in 2010 the amount was to the tune of Rs.3.00 lakh.

The group leaders informed that different types of pads were made. The general type consisted of 4 pads cost Rs.260 and sustain for one year. Another type is double XL for four pieces, the cost is Rs.400 and it can be used for one year. The third one is 'FeelFree Soft' for four pieces the price is Rs.600 which can be used for three years. The other variety is Padfree normal which can be used for three years and each pad costs Rs.150. And all pads every time are washable as already mentioned. It is pertinent to mention that the prices are based on the study carried out in December 2018. 


\section{Conclusion and suggestion:}

The research study reveals that by producing the sustainable pads many families have been benefitted. As direct benefit 40 women members of 40 households were eking out their livelihoods by producing the pads. And about 20,000 ladies and girls have been using these pads (as reported) so from health and hygiene point of view thousand females have been benefited.

It is suggested that since the pads have great utility so based on social, cultural and economic aspects massive campaign may be made so that such venture may be set up across the country.

\section{References:}

[1]. https://www.outlookindia.com/website/story/menstrual-hygiene-in-india

[2]. http://www.gramalaya.in/about_gramalaya.php

[3]. https://www.feelfreeclothpads.com/about 